\title{
ICT BASED PREFERENCE GRADIENT MODEL- A STUDY FOR POST-PANDEMIC TOURISM AND ENVIRONMENT MANAGEMENT IN ANDAMAN \& NICOBAR ISLANDS
}

\author{
S. Raji \\ Lecturer, Civil Engineering Department, \\ Dr. B. R. Ambedkar Institute of Technology, Port Blair, A\&N Islands, India \\ Email: rajipradeepportblair@gmail.com
}

\begin{abstract}
This paper is an attempt to illustrate application of Information and Communication Technology (ICT) framework as an implement for focusing sustainable livelihood, in post pandemic period, through resource management in a tourism dependent economy of Andaman \& Nicobar Islands. The pandemic as elsewhere has affected the economy of the Islands and therefore, post pandemic trade and business will require change in the paradigm of operational strategies. The internet deficient territory was dependent on macro level enterprises at mainland for supply of business whereas, now the new digital highway link between mainland India and the Islands have envisaged the diffusion of ICTs in micro level enterprises which can be linked through various societal levels for crafting extensive network of Management Information System (MIS). The paper recommends for ICTs based structure that can be inherently used in all trades, comprising of both macro and micro level enterprises, contributing to the tourism based economy of the Islands. The framework is proposed to merge all strata of businesses, forming the tourism activity chain, by ICT applications thus the flow of information can be shared with a large MIS enabling optimum usage of peripheral facilities in all tourist intensive islands of the territory. The study drew the conclusion that, in the age of climate change and pandemic challenges, an institutional framework in the form of Information and Communication Technology Network Framework (ICTNF) and Preference Gradient Model (PGM) is essentially required to link formal and non-formal centre of population to create sustainable livelihood.
\end{abstract}

Key word: ICT, MIS, Environment, Economy, Livelihood, Ecosystem, ICTNF, PGM

\section{Introduction}

Many a researchers have emphasised the application of Information and Communication Technology (ICT) to assess the livelihood framework (e.g., Albu and Scott 2001; Chapman et.al.2001; Info Dev 2005). In all such explorations the livelihood framework was made to adapt ICT oriented analysis. Initially the purposes of all such experimentations were to understand and evaluate the causes of poor livelihood conditions leading to poverty and to offer a pragmatic approach to investigate the conditions. The outbreak of Covid 19 pandemic has affected the socioeconomic set up of communities disrupting the economic growth and business environment (Das Rakshit et.al. 2020). These islands are no different in receiving the impact of downturn in its tourism business due to lockdowns and pandemic related closures. The union territory of Andaman \& Nicobar (A\&N) Islands have known for its historic background in Indian freedom struggle and for tourism opportunities. Thus, tourism being the only industry feeds microenterprises and related livelihood opportunities. Since microenterprises have known for their significant contribution towards socio-economic development (Qureshi, 2005; Ritchie \& Brindley, 2005) for any community or region therefore strategies need to 
be designed for their survival and growth in post pandemic period. The islands unlike the other part of the world, were deficient in internet facilities. The laying of undersea cable forming the digital highway between mainland India and Island capital of Port Blair has unlocked the otherwise foreseen opportunities which can revolutionise the digital intrusion. Therefore, an Information and Communication Technologies (ICT) supported framework strategy will now augment economic sustainability and environment management in post pandemic scenario. The paper aims to provide a contribution to theorizing Information and Communication Technology Network Framework (ICTNF) as a suitable framework of analysis, taking a case study of traffic and tourism related livelihood conditions of a well sought tourist destination, Swaraj (erstwhile Havelock) Island, as an important potential area where application of ICT framework can create a sustainable environment for economic activities.

\section{Objectives}

The paper is structured as follows, the first section presents a brief review concerning micro environment components of the study area which is diffusing ecosystem with economy. The following section outlines the principal components of the livelihood framework and matrix with the role of information and communication in livelihood analysis and MIS for monitoring and management. A number of MIS system has been incorporated into the framework taking into consideration the pandemic situation and employing a socio technical approach that prioritizes a linkage of information and communication flow for taking appropriate decisions for resources utilisation and livelihood. Further, Preference Gradient Matrix (PGM) is also proposed to deal with overcrowding of road and travel infrastructure.

\section{Macro and Micro Environment of Livelihood in Swaraj (Havelock) Island}

There are two types of microenterprise occupation and (Duncombe and Heeks 2002; Shaw 2004) that are survivalist and entrepreneurs. Survivalists are drawn into business enterprise by the lack of other income generating activities. In Swaraj (Havelock) Island, as shown in Figure-1, as similar to other tourist focussed islands of $A$ \& $N$ Islands, the Macro environment created by the entrepreneurs outline the majority of microenterprises diffusing the fragile ecosystem of the islands with economy. They are commonly located in those islands where tourism offers livelihood opportunities to the local population and thus they form macro environment. In addition to macro and micro entrepreneurs there are typically unregistered occupants earning livelihood with services related to tourism activities viz; fishing, tourist vehicle services, commercial transport and construction who constitute what is generally termed as "informal sector". They are commonly founded upon the direct services to tourists creating microenvironment.

The "seasonality" of tourism industry in A\&N Islands is another critical factor (MoTAC-Department of Tourism, 2003) which will have major impact on livelihood and economic environment in near future due to ongoing pandemic. Both south-west and north-east monsoon contributes an annual rainfall over $3000 \mathrm{~mm}$ to A\&N Islands. The climate change concerns like receding monsoons, cyclones and related impact on modes of travel mainly restricts the tourism season for 5 to 6 months a year (November to April). Therefore, tourism options/ season for round the year need to be strategized to survive the economic fissure created by pandemic. Entrepreneurial enterprises may employ skilled manpower and use more IT related technologies for business gain. On the other hand, survivalist enterprises may use smart devices- mobiles/apps for linking livelihood activities through ICT based MIS framework. Thus, informal sector will interact more effectively with established local markets whereas the formal sector can connect to mainland and global markets. There is also various scope of creating effective macromicro links through livelihood approach framework (Schulpen and Gibbon 2002). The segmental process showing the existing inter -relation between these two sectors dominating the Island economy can be understood from Figure-2 
Figure 01: Swarajdeep (Havelock Island)

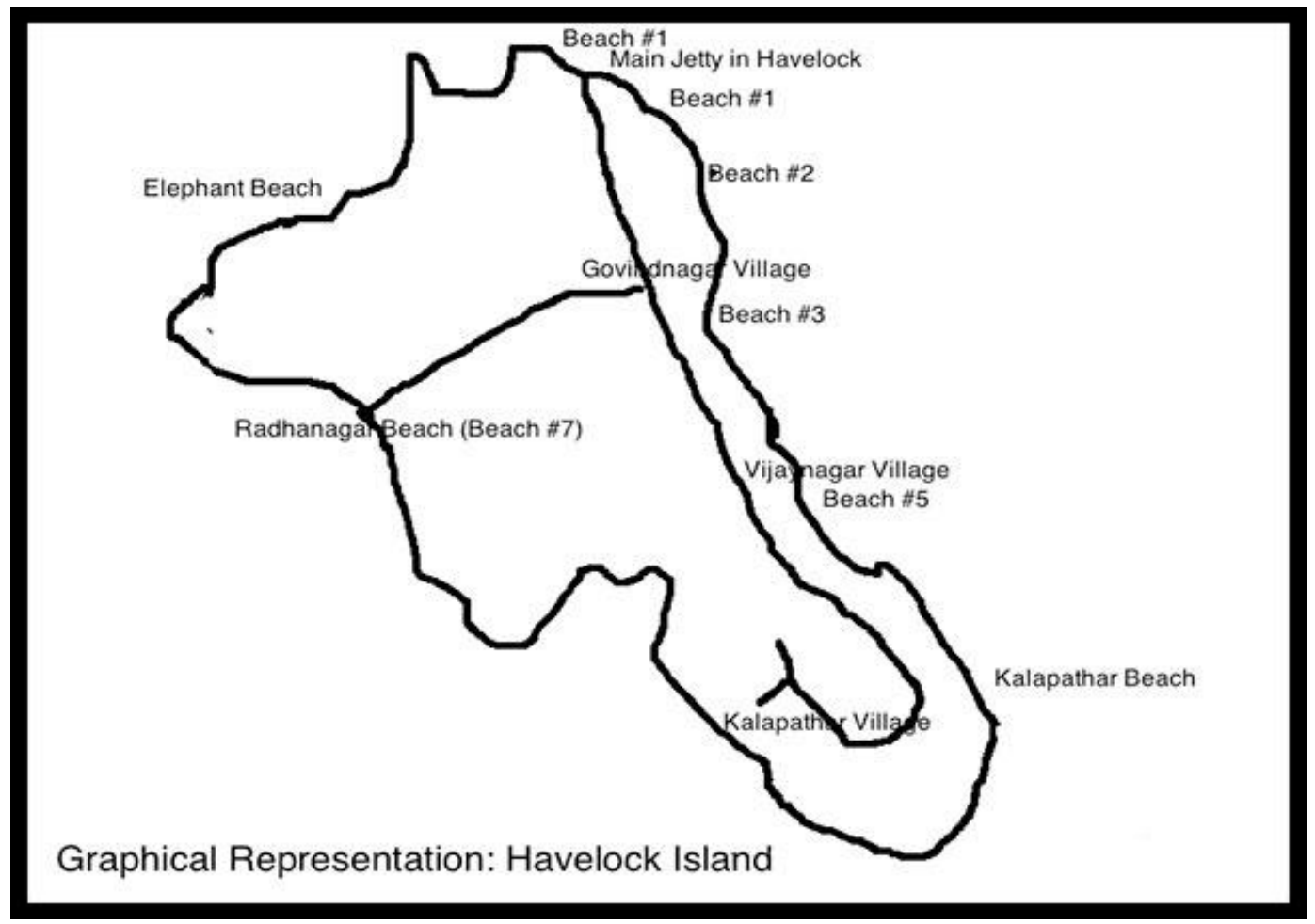

Figure 02: Segmented Process Showing Relation Between Formal and Informal Sector

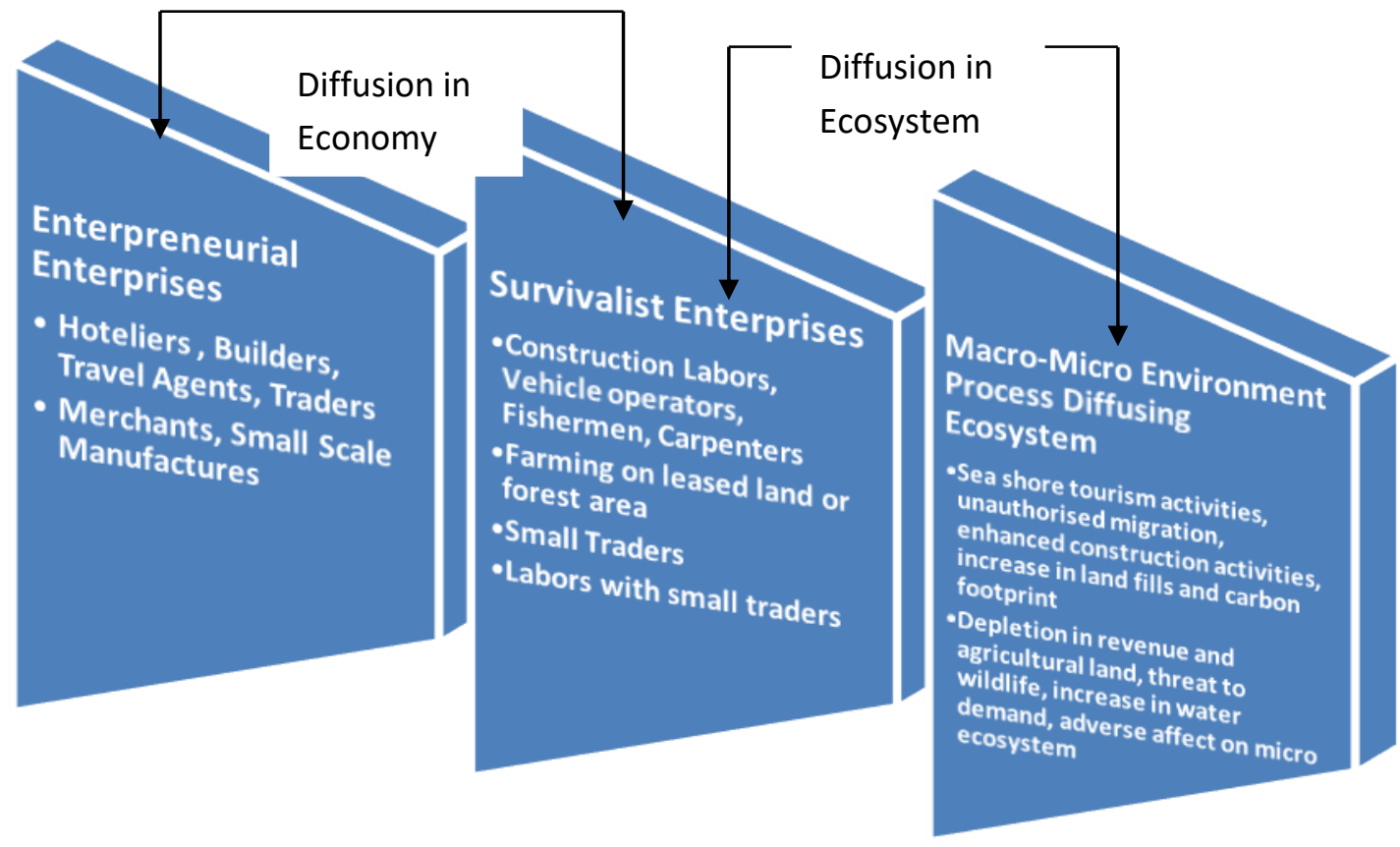

The Macro-Micro environment can be approached and evaluated analytically as well as functionally (Richard Duncombe,2007). The analytical role focuses on accessing and assessing empirical evidence (both quantitative and qualitative) to understand livelihoods -by researchers, project/program planners and policy makers. However, the 
functional role focuses on action -the manner in which information is used within livelihood strategies by themselves for the structures and processes that impinge their lives and to create favourable outcomes. Thus analytical and functional role can be merged with ICT tools to enhance the productivity and to maintain an MIS for keeping a check on anthropogenic activities affecting the fragile environment of these islands.

\section{Factors contributing to Tourism Economy in Swaraj (Havelock) Island}

The inflow of capital happens along the Tourism Value Chain (MoTAC-Department of Tourism, 2003). This framework comprises a common platform viz; infrastructure and other requirements, for both macro and micro level enterprises for their capital inflow. Thus inter and intra level diffusion of service and other tourism related activities within the chain make macro and micro level enterprises mutually dependent. The Tourism Vale Chain as shown in Figure-3 has four levels.

\section{Figure 03: Tourism Activity Chain}

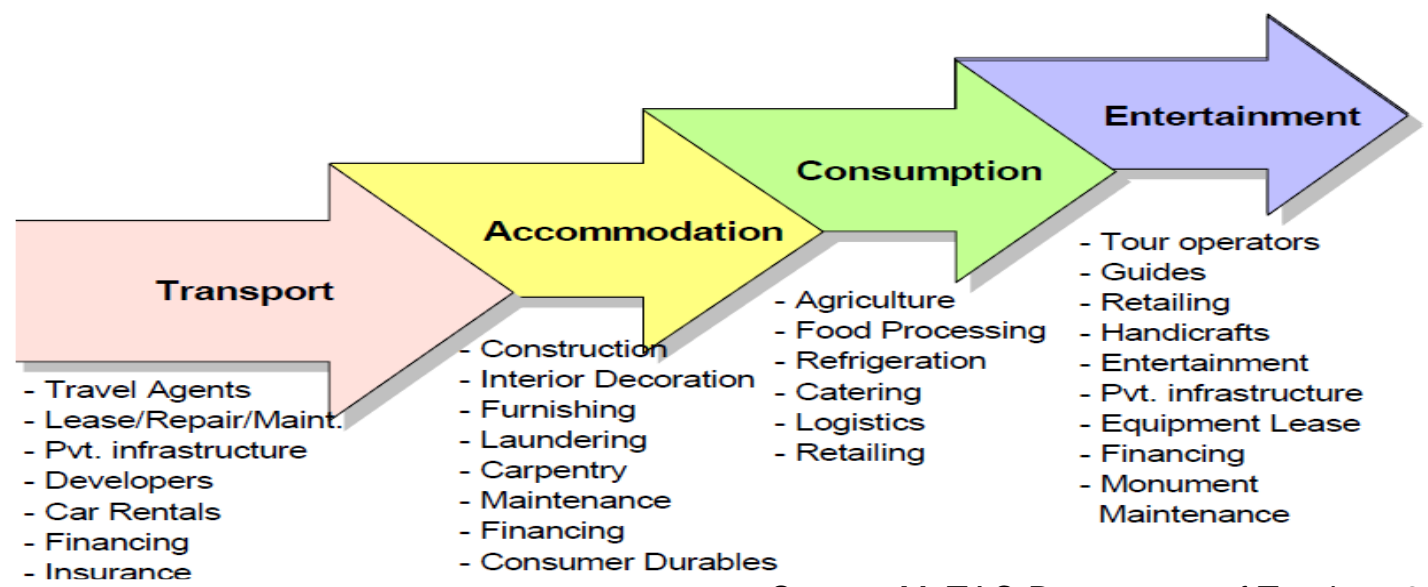

Source: MoTAC-Department of Tourism, 2003

Among all the permissible tourist destinations of A\&N Islands-Swaraj (Havelock) Island is the favourite destination for both national and international tourist visiting the union territory (Nagabhatla Nidhi et.al.2004). The pristine beaches, rated as one of the best beaches in the world, under -sea coral reef and open zone of surrounding shallow waters are the major attractions of this Island. Island location with its tourist attractions envisaged development of good quality infrastructure in the island. The sudden surge in tourist inflow propagated the "Economic leakages" (MoTAC-Department of Tourism, 2003) which is very common in small island economy, viz; travel and related facilities planned and managed by non-islanders and non-locals from mainland. Further, discovery of tourism potential of Swaraj (Havelock) Island by established enterprises of mainland created macro environment which comprises the initial steps of tourism chain. The tourist inflow and the subsequent vehicle population forecast carried out before the pandemic is shown in Figure 4.

The upper level of tourism chain in turn was fed by local survivalist enterprisers and the process set off the burden on limited resources available in the small island. It included over plying of tourist vehicles surpassing the capacity of rural roads in the islands, loss of farming land, overcrowding of existing tourism facility and related environment pollution viz; plastic waste accumulation, drinking water scarcity etc. show Therefore, ICT tools can play an important role in forming the framework of MIS for regulating the developmental as well as economical activities in the island during the post pandemic phase. 
Figure 04: Forecast for Non-Islander tourist and vehicle population in Swaraj (Havelock) Island

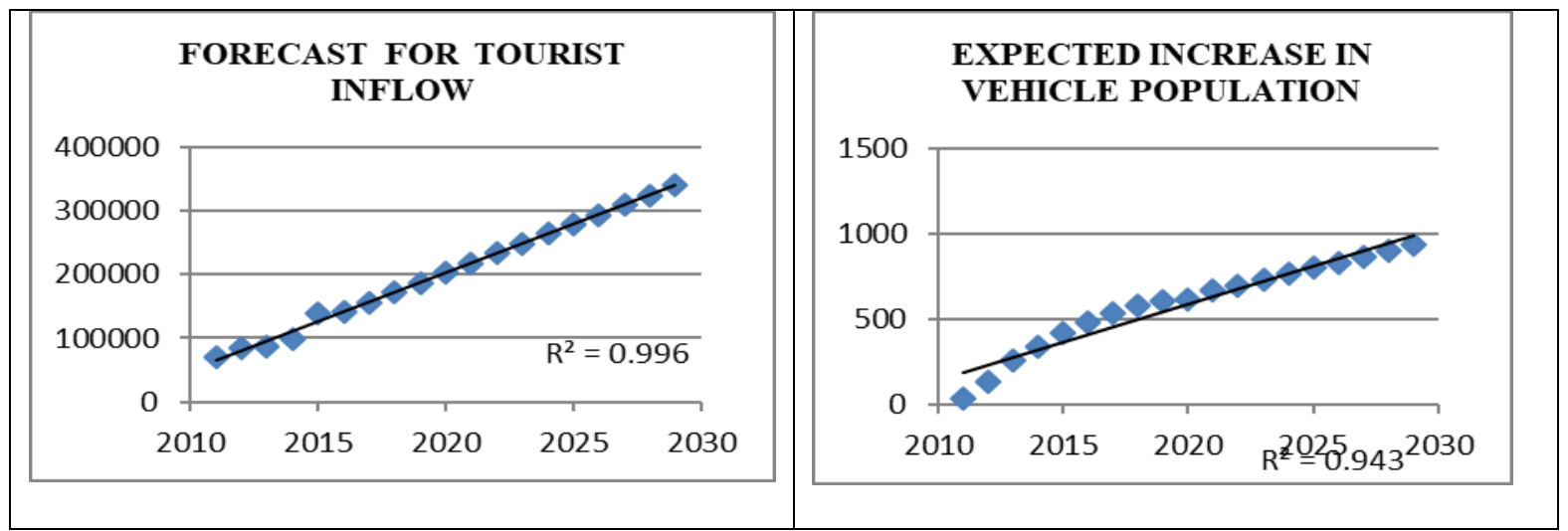

\section{ICT Application for Macro-Micro Environment}

The bottom up modal livelihood measures need to be adopted from micro level, where individuals, families, households, or groups create their own e- strategies within given context of vulnerability. The vulnerability can be in context of prevailing regulations/ government policies, change in tourism pattern, Climate change conditions, resource availability and economical opportunities. Therefore, ICT providers need to understand the key analytical role of vulnerable factors focussing the functional role that involves communicating information to primary respondents. If the respondents are themselves going to be the recipients of such contextual information (or any type of information other than vulnerability context) to make livelihood and enhancing productivity by use of it, then it must be assured that they require more than delivery data. This can be achieved by applying Information and Communication Technology Network Framework (ICTNF), as shown in Figure -5 , firstly by creating the database of existing environmental details and thereby providing the MIS for Macro and Micro Enterprises to adopt new e-economic and e-service based livelihood. Further, the framework should have in-built monitoring system to check the threshold of resources and accordingly policies and guidelines should be framed for attaining sustainability in both natural and economic environments.

Figure 05: Information and Communication Technology Network Framework (ICTNF)

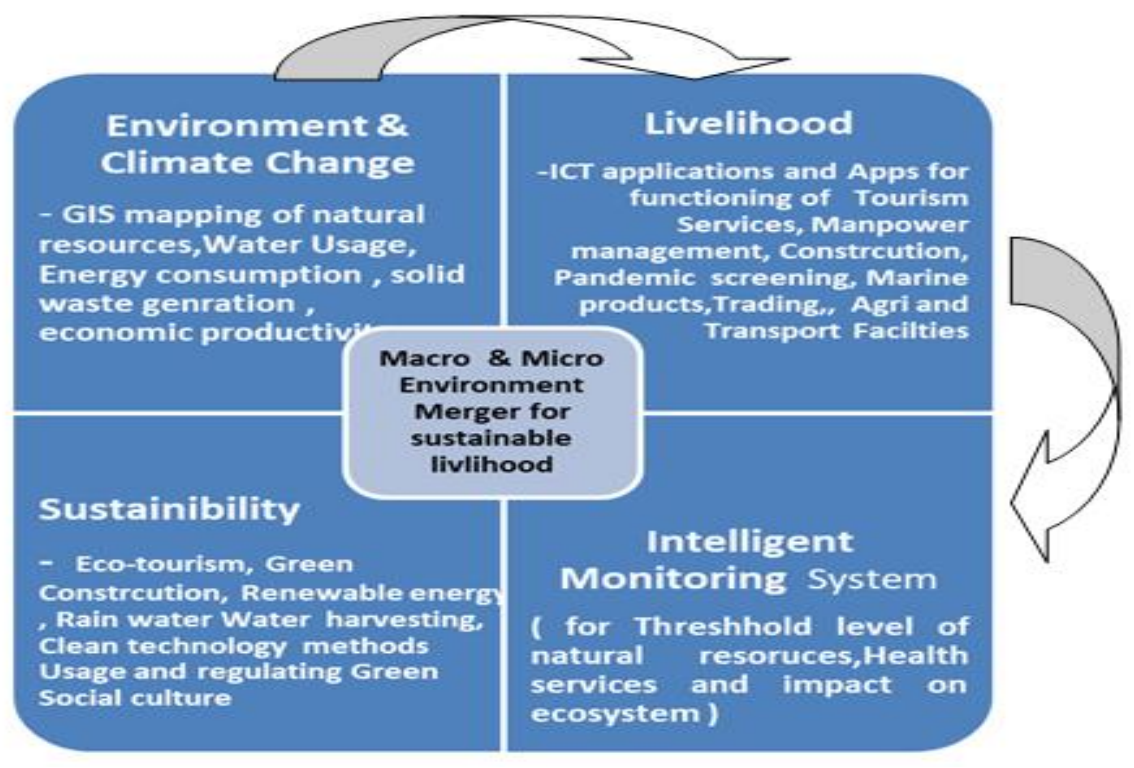


The study also attempted for proposing an ICT based Preference Gradient Model (PGM), as shown in Figure-6, adopting ICT to explicate the types of tourist and their preferences for transport facility by creating four levels of preference gradient to envisage the expected service and to regulate the green concept in visiting tourists.

Figure 06: Preference Gradient Model (PGM)

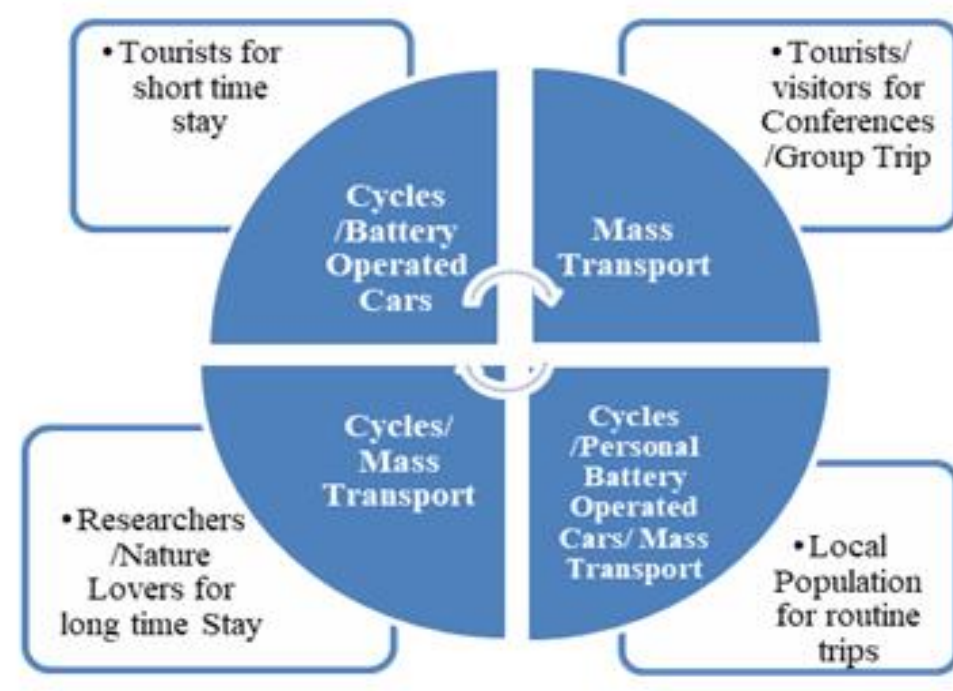

Thus mapping of existing resources (including physical, monetary and social) will allow accessibility to realistic information to formal sector as well as survivalist informal sector. n. Thus, ICT applied framework and matrix can be exercised for monitoring and checking the vulnerability of the individual livelihood within the system as well as with respect to the environment. The proposed ICTNF will involve the critical parameters affecting environment and livelihood and can be adopted in other tourist inflicted islands of the territory.

\section{Conclusion}

There is an array of applications of ICT tools which can be employed to strategise synchronization of extractive natured livelihood and biodiversity dependent economy of these islands. Firstly, the ICT applications mentioned in the paper can be initiated for formal sector and after creating awareness about the e-based MIS system, the same can be applied to informal sector - the survivalists who are mainly dependent on the macro environment. Therefore, in the era of internet and smart technologies ICT can easily intrude into macro-micro environment of livelihood and the factors affecting sustainability can be measured, monitored and regulated accordingly. Environment resource depletion and utilisation impact assessment through ICT will assist in prediction of future prospects of economical activities and in framing policies to sustain effective livelihood.

\section{Future Scope}

Various model/system such as Preference Gradient Matrix, as proposed for transport facilities, can be designed and implemented for other sectors such as water supply and sanitation, waste management and use of renewable energy. Planning and designing systems for adoption of Green Construction and reducing carbon foot print can be further explored in future course of research to attain sustainable growth of tourism industry in the union territory of Andaman \& Nicobar Islands.

\section{References}

1 Albalate, D., \& Bel, G. Tourism and urban public transport: Holding demand pressure under supply constraints. Tourism Management, 31(3), 2010. Pp-425-433.

2 Albu, M., and A. Scott. (2001). Understanding Livelihoods that Involve Micro- 
Enterprise: Markets and Technological Capabilities in the SL Framework. Bourton, UK: Intermediate Technology Development Group. Available at www.itdg.org/docs/ advocacy/micro-enterprise-livelihoods.pdf

3 Ashworth. Gand PageS. J; Urban tourism research: Recent progress and current paradoxes, Elsevier, Tourism Management, Vol. 32, 2010, pp.2-8.

4 Chew, H., llavarasan, P. and Levy, M. (2010) The Economic Impact of Information and Communication Technologies (ICT) on Microenterprises in Development Context. The Electronic Journal on Information Systems in Developing Countries, 44, ,4, 1-19.

5 Duncombe, R. A., and R. B. Heeks. (2002). "Enterprise across the Digital Divide: Information Systems and Rural Micro-enterprise in Botswana." Journal of International Development 14(1): 61- 74.

6 Gill. N \& Bharath. B.D., "Identification Of Optimum Path For Tourist Places Using Gis Based Network Analysis: A Case Study Of New Delhi”, International Journal of Advancement in Remote Sensing, GIS and Geography, Voll,2013,pp.2-3

7 Heeks, R. (1999). "Information and Communication Technologies, Poverty and Development." Development Informatics working paper no. 5, Institute for Development Policy and Management, University of Manchester. Available at www.sed.manchester.ac.uk/idpm/publications/ wp/di/index.htm

8 InfoDev. (2005). Framework for the Assessment of ICT Pilot Projects: Beyond Monitoring and Evaluation to Applied Research, Information for Development Program (InfoDev), Washington, DC: World Bank. Available at

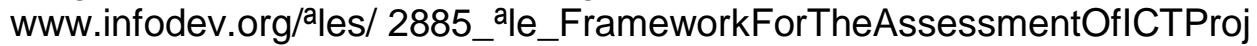

9 Kumar Praveen, Singh \& Reddy Dhanunjaya, "Advanced Traveler Information System for Hyderabad City", IEEE Transactions on Intelligent Transportation Systems, Vol. 6, No. 1, March 2005, pp 03-05

10 Ministry of Tourism \& Culture - Department of Tourism (MoTAC-Department of Tourism), Govt. Of India, (2003) Final Report on Perspective Plan for Tourism in Andaman \& Nicobar Islands , 35-45

11 Nagabhatla, Nidhi., Porwal, M.C., Padalia, Hitendra \& Roy, Parth Sarathy (2004)." "Assessing impact of tourism in the Havelock Island (Andaman and Nicobar Islands) using RS and GIS", Research Gate Conference Paper, 3-10 Available at https://www.researchgate.net/publication/266739128,

12 Qureshi, S., Kamal, M., \& Wolcott, P. (2008). Sustainability of Information Technology Therapy on Micro-Enterprise Development. Proceedings of the 41st Annual Hawaii International Conference on System Sciences, Hawaii.

13 Rakshit Debdas \& Paul Ananya (2020). Impact of Covid-19 on Sectors of Indian Economy and Business Survival Strategies. International Journal of Engineering and Management Research, 10.3.8, 3-4

14 Ritchie, B., \& Brindley, C. (2005). ICT adoption by SME: implications for relationships and management. New Technology, Work and Employment, 20(3), 205-216

15 UNESCO Report, Sustainable Tourism Development in UNESCO Designated Sites in South-Eastern Europe, 2007, pp 02-14 